Environment Conservation Journal 15(1 \&2) 123-133, 2014

ISSN 0972-3099 (Print) 2278-5124 (Online)

Abstracted and Indexed

\title{
Quantitative and physico-chemical characterization of domestic solid waste in a typical Nigerian municipality
}

\author{
Nnaji Chidozie Charles
}

Received:26.11.2013

Revised:28.04.2014

Accepted:02.05.2014

\begin{abstract}
In the present study solid waste were collected from households, banks, restaurants, higher institution, open dump and a final disposal site of Nigerian municipality with a view to determining waste generation rate, relative waste compositions and its physicochemical properties. During the course of study average rate of solid waste generation was found to be $0.39 \mathrm{Kg} /$ capita/day. A highly negative correlation $\left(R^{2}=0.99\right)$ was observed between per capita waste generation and household size (n) for $n \geq 4$. The waste collected from households consisted of putriscibles $(47 \%) 11 \%$ water proof, $6 \%$ plastics, $4 \%$ glass, $3 \%$ clothes/textiles, $2 \%$ diapers and $19 \%$ of other unclassified materials. Due to the activities of scavengers, the relative proportion of recyclables such as plastic, glass and metals decreased as waste materials transited from households to the final dumpsite via open dumps, while the other fractions increased. It was found that $79 \%$ of the solid waste generated can either be recycled (32\%) or composted (47\%) however; only $12 \%$ is recovered for recycling/reuse while composting is hardly practiced. The three most important factors responsible for relative differences in the composition of solid waste obtained from different sources are scavenging, biodegradation and leaching. The putriscible fractions from households, curb sides and the final disposal site were assessed for their suitability for composting using the clean index (CI) criteria. It was found that the final disposal site with a $C I$ of 3.3 on a scale of 5 was a better source of compost material than freshly generated household waste $(C I=2.9)$ and curb side waste $(C I=2.4)$.
\end{abstract}

Keywords: clean index, dumpsite, heavy metals, recycling, scavengers, solid waste

\section{Introduction}

The critical and most immediate problems facing developing countries and their cities are the health impact of urban pollution (Momodu et al, 2011. Increasing waste generation rates due to population growth, changing lifestyles of people, development and consumption of products with materials that are less biodegradable have all increased the burden of municipal solid waste management (Asase et al, 2009). Many developed countries have successfully controlled municipal solid waste and have even gone a step further by putting them to such good use as energy and material recovery while many low income countries are still grappling with the challenge of municipal solid waste. It is therefore not uncommon to be confronted with a miasma of decomposing solid waste dumps in many cities. Open dumping has been implicated in a variety of environmental and health hazards such as fire outbreak, groundwater and surface water contamination, air pollution, rodent multiplication

\section{Author's Address}

Department of Civil Engineering, University of Nigeria, Nsukka

Email: chidozie.nnaji@unn.edu.ng and foul odour. In addition to defacing the environment, these dumps provide a comfortable harbourage for disease-causing vectors. Henry et al (2006) reported an outbreak of diarrhoea in Kenya as a result of consumption of vegetables irrigated with surface water contaminated by solid waste dumped upstream. During the rainy season, enormous amounts of leachates are produced in these waste dumps. Septic tank effluents and leachates from open dumps pose the greatest threats to both groundwater and surface water resources in developing countries. Apart from leachate production and vector harbourage, open dumps are usually set ablaze either by scavengers in a bid to get rid of unwanted materials in order to facilitate their search for recyclables; or residents seeking to create space for more waste. Nas and Bayram (2008) observed that most developing countries resort to open dumping because of its simplicity and low cost. However, this cost saving is more than counteracted by the far reaching health and environmental consequences associated with open dumping. Open dumps are a necessary evil in the light of inefficient waste management. The 
dynamics of open dumps proliferation require an independent study. However, the reason for open dumps proliferation is threefold: (i) waste generated must be rid of; (ii) nobody wants to travel far from home to dispose of waste; and (iii) waste management authorities do not have the facilities and manpower to cope with existing dumps; so when these dumps overflow, people naturally start dumping in a new place. Other factors militating against the efficiency of municipal waste management are waste disposal habit, corruption, poor work attitude, and inadequate plants (Adewole, 2009). The result of this is that only 50 $70 \%$, or even much less, of waste generated is collected (Ogwueleka, 2009). Effective waste management through municipal waste composition studies include: (i) estimation of material recovery potential; (ii) to identify sources of components generation; (iii) to facilitate design of processing equipment; (iv) to estimate chemical, physical and thermal properties of waste; and ( $\mathrm{v}$ ) to ensure compliance with national laws (Gidarakos et al, 2006; Lisa and Anders, 2008). In most developing countries, waste management authorities do not have the appropriate strategies to estimate waste generation, characteristics and composition. Where such data exist, they are usually the result of independent studies by individual researchers.

\section{Materials and Method}

The methodology employed in this research work consisted of four stages during which about $460 \mathrm{Kg}$ of solid waste were collected, sorted and analyzed. The first phase was a preliminary survey of waste management practices in the municipality and interviews with scavengers. The second phase involved collection of waste from banks, restaurants and educational institution (University), in order to determine their relative compositions.

In the third phase which ran concurrently with the second phase, black polythene bags were distributed to randomly selected homes for waste storage. They were requested to store their domestic waste in the polythene bags for a period of 48 hours and to knot the mouth at the expiration of 48 hours. They were told not to transfer previously collected waste into the bags. Thereafter, the bags were retrieved and sent to the Laboratories of the Department of Civil Engineering University of Nigeria, Nsukka for sorting and subsequent analyses. A total of 119 bags were retrieved instead of the 150 originally intended. This method of solid waste generation survey was deemed most suitable for a developing country because of the "scavenging" effect. The quantity and composition of waste at curbside dumps is usually drastically distorted due to the activities of scavengers so that it becomes very difficult to accurately determine waste composition and generation rates using waste dumps as was done by Qu et al (2009). Lebersorger and Schneider (2011) noted that the obvious option to determine the proportion of food waste is to conduct a household waste composition analysis. They further noted that the identification of waste components from collection vehicles was difficult and inaccurate because of the process of mixing and compaction. In order to ascertain the effects of scavenging on the composition of solid waste, wastes were collected from a curbside dump and the final disposal site. This was the fourth phase.

The wastes collected from banks, restaurants, institutions were merely sorted into the following components: metals, plastics, food waste, diapers glass/bottles, clothes/textiles, water proof paper and others after sorting, their relative composition was determined as a percentage. The household wastes were first weighed on a weighing balance and the weight divided by the 2 times household size, since the duration of storage was two days. After weighing, the wastes were sorted into their generic types and their bulk densities were determined (Figure 1).

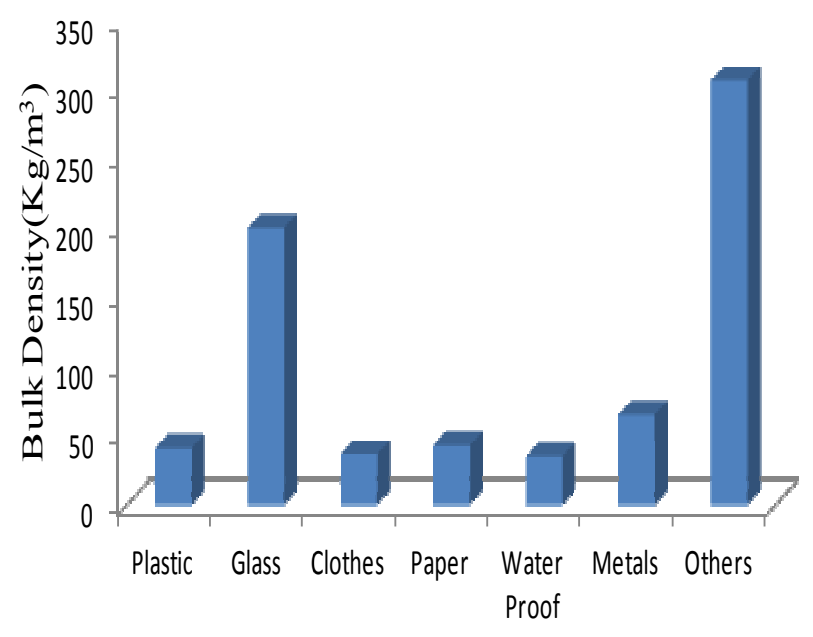

Solid Waste Fraction 
Figure 1: Bulk density determined for various waste fractions

The same treatment was given to wastes collected from curbside dump and final disposal site. Next the compostable fraction of the wastes from households, curbside dump and final disposal site were separately shredded. After shredding, each was thoroughly mixed, coned and then quartered. Four replicates (one sample from each quarter) were used for moisture content determination in an air oven at $105^{\circ} \mathrm{C}$ for 24 hours. One quarter from each of the three waste sources was air dried and then stored for subsequent determination of oxidizable carbon, total organic carbon, organic matter, nitrogen and heavy metals (lead, chromium, cadmium, zinc, copper and nickel) using three replicates for each analysis.

Using material balance, the maximum residence time of waste from the point of generation to the final disposal site can be estimated as

$$
R_{\theta}=\frac{C F}{N V}+\frac{N_{c v} V_{c v} T}{F_{c v} V_{w} T_{t r i p}}
$$

Where $R_{\theta}$ is the average waste residence time (days) between waste generation and disposal at final dumpsite, $C$ is the capacity of household waste bin, $V=$ per capita rate of waste generation, $N=$ household size, $N_{c v}=$ number of collection vehicles, $V_{c v}=$ capacity of collection vehicle, $T=$ number of work hours per day, $F=$ waste bin utilization factor $V_{w}=$ is the total volume of waste generated $\left(\mathrm{m}^{3} /\right.$ day $), F_{c v}$ is truck compaction factor, $T_{\text {trip }}=$ average length of time per trip from curbside to final disposal site. The first term represents the maximum number of days waste resides in the bin before transfer to the curbside or open dump. The second term represents the number of days the waste subsequently spends at the curbside before being carted to the final disposal site.

The suitability of the compostable fractions for composting was determined using the clean index criteria (Saha et al, 2010) as given below

$$
C I=\frac{\sum_{n}^{i=1} S_{i} W_{i}}{\sum_{n}^{i=1} W_{i}}
$$

Where $S_{i}$ is the score assigned to the compost fraction from each source based on heavy metal concentration and $W_{i}$ is the weighting factor assigned to each heavy metal based on phytotoxicity and human ecotoxicity potentials.

\section{Results and Discussion \\ Waste Generation}

Generally, waste management in Nsukka municipality consists of generation, transfer, collection, disposal, sorting and recycling. The key players at the various stages of waste management are: households- generation and transfer; municipal waste management authority - collection and disposal; the informal sector (scavengers) - sorting; and the industry - recycling. From this study, the mean rate of solid waste generation was estimated at $0.39 \mathrm{~kg} / \mathrm{capita} / \mathrm{day}$ with a standard deviation of $0.25 \mathrm{Kg} /$ capita/day. This value is roughly within the range of waste generation for low income countries. Though factors affecting solid waste generation rate were not the focus of this study, a strong correlation $\left(R^{2}=0.84\right)$ was found between the rate of solid waste generation and household size. Figure $2 \mathrm{a}$ shows that maximum rates $(0.48 \mathrm{Kg} /$ capita/day $)$ of solid waste generation were recorded for households of size between three (3) and four (4). As household size increases beyond these values to seven (7), rate of solid waste generation per capita drops to about $0.19 \mathrm{Kg} / \mathrm{day}$. The reason for this is that households of one or two people are occupied by single individuals, roommates or, at the most, new couples with no children. These groups of people usually prefer to eat at restaurants. The result is a drastic reduction in per capita waste generation at household levels, as Figure 3 shows that $48 \%$ of household solid waste is food waste. However, as couples begin to have children, they are forced to start preparing their own food, causing an increase in per capita rate of solid waste generation. Hence, it can be deduced that a strong negative correlation $\left(R^{2}=0.99\right)$ exists between family size (rather than household size) and per capita solid waste generation. In order to buttress this deduction, a plot of family size (beginning from $n=4$ ) has been presented (Figure $2 b$ ). This implies that as family size increases, per capita waste generation decreases. Qu et al (2009), who also noted that a negative correlation existed between household size and rate of solid waste generation per capita, attributed this to effect of common consumption. 


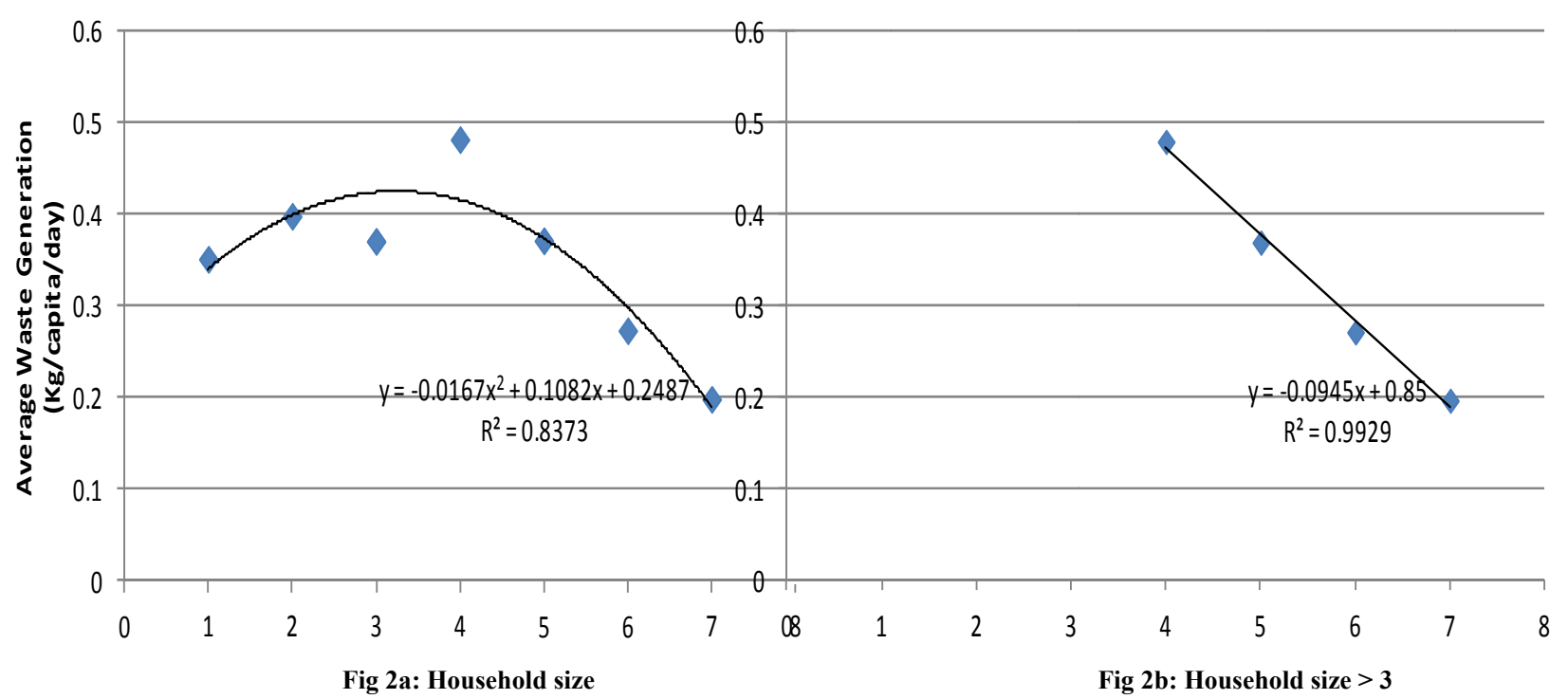

Figure 2a: Effect of household size on per capita waste generation

Figure 2b: Effect of family size on per capita waste generation $(n>3)$

\section{Solid Waste Composition}

Results obtained from waste composition studies depend on source of the waste samples used. In many developing countries, composition of waste is altered as it leaves the home for final disposal sites via open dumps. This can be attributed to the activities of scavengers and occasional burning of open dumps. Hence, it is crucial to ascertain the pattern of material flow from households to open dumps. As in all developing and even most developed countries, food waste represented a large fraction of household waste in Nsukka. Figure 3 shows that almost half (47\%) of total solid waste generated by households was food waste. This was remotely followed by water proof $(11 \%)$, paper $(6 \%)$, plastic, glass and metals (4\% each), clothes/textiles $(3 \%)$ and then diapers $(2 \%)$. The other $19 \%$ constituted of a mixture of sand, yard sweepings, wood, hair/wool and a lot of other unclassified materials. The proportion of food waste in municipal solid waste is generally taken as an indication of living standards, but it also portrays the pattern of living. High proportion of food waste also shows that people still maintain the traditional practice of food preparation at home, rather than the modern trend of consumption of packaged food.The fraction of food waste obtained in this study is in the same order of magnitude as those obtained in previous studies for cities in other parts of the world. Gidarakos et al (2006) obtained a value of $39.15 \%$ for the Island of Crete;

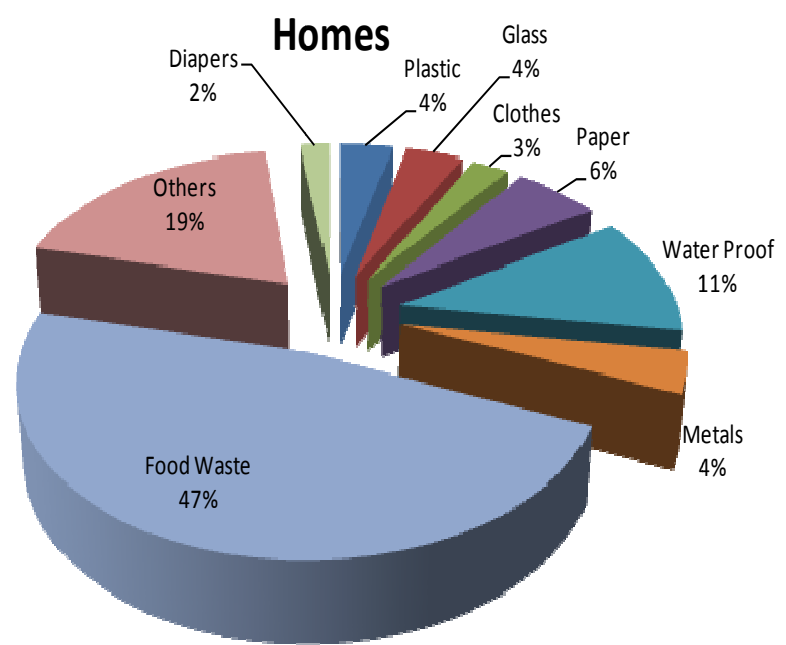

Figure 3: Composition of freshly collected solid waste from homes

Sha' ato et al (2007) obtained 49.2\% for Makurdi in Nigeria; and Nwachukwu (2009) obtained 40.5\% for Onitsha in Nigeria. An even higher proportion of food waste $(69.3 \%)$ was obtained for Beijing by Qu et al (2009). It needs to be pointed out that the proportion of food waste obtained by various researchers might depend on their definition of food waste. In this study food waste was defined as 
follows: any putrescible material used in the preparation of food, leftover food and remains/peels of fruits. The fairly high proportion of water proof is as a result of its indiscriminate use as a packaging material. Firdaus and Ahmad (2010) observed that packaging materials are becoming an increasingly important component of municipal waste. Figure 4 shows the composition of waste at curbside open dumps. Due to the activities of scavengers, the relative proportions of recyclable materials such as plastic, glass and metals dropped from $4 \%$ each to $2 \%, 1 \%$ and $3 \%$ respectively. This resulted in increase in the relative proportions of food waste and diapers. The proportion of materials such as water proof and clothes/textiles remained the same because they are of no commercial value to the scavengers. The relative composition of solid wastes from final disposal site is shown in Figure 5. There was a drastic increase in the fractions of diapers $(34 \%)$, water proof $(21 \%)$ and paper $(7 \%)$. These fractions in addition to clothes/textiles have no recycling/reuse potential in the municipality, hence their abundance at the final dumpsite. Two factors are responsible for the drastic increase in the proportion on diapers. The first factor has been previously mentioned - lack of recycling potential. The second factor is that diapers contain super absorbent particles made from cellulose pulp. A disposable diaper can absorb 15 times its own weight of water. Since this study was conducted during the rain, the diapers found at the dump sites were saturated with water, thus grossly exaggerating their weights.

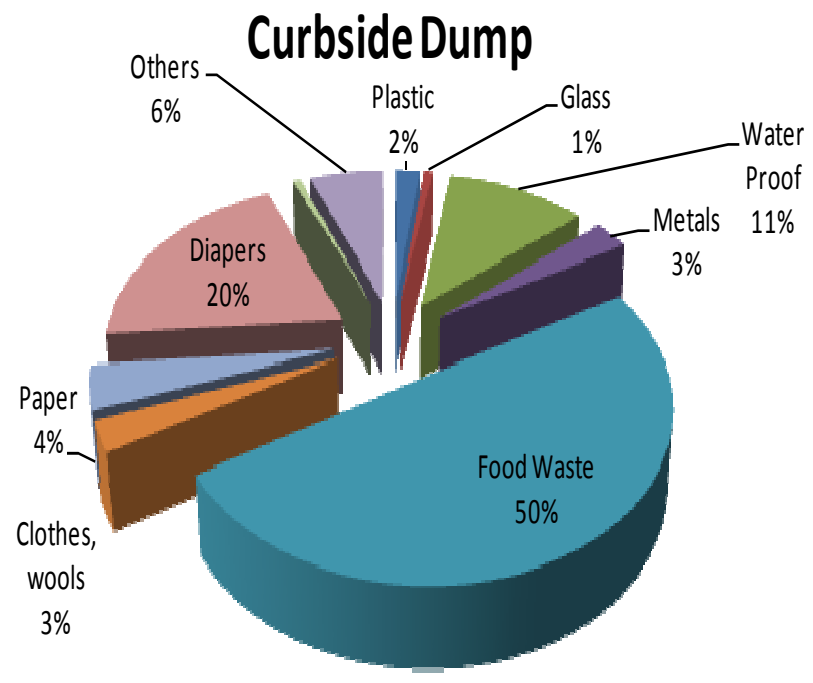

Figure 4: Solid waste composition at Curbside open dump

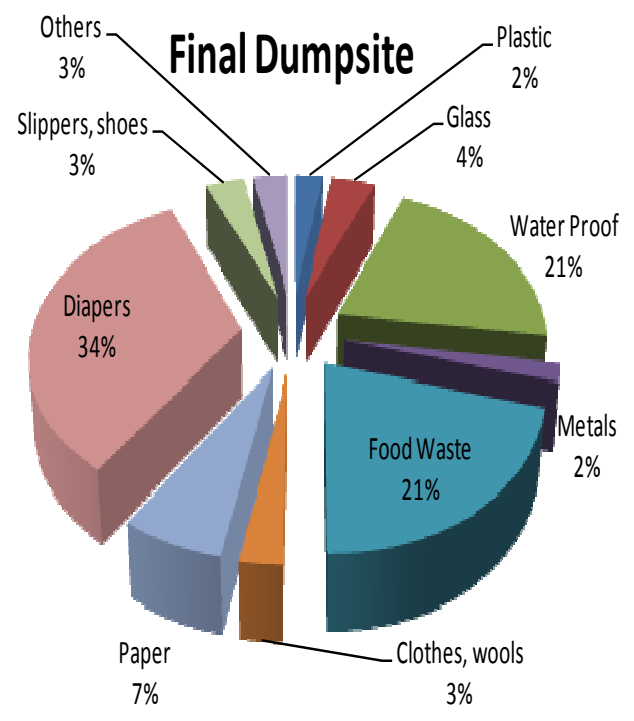

Figure 5: Solid waste composition at final dumpsite

The drastic reduction in the proportion of food waste $(21 \%)$ was due to biodegradation and scavenging by dogs and other stray animals. In Nsukka, it can take about two weeks or more for waste to arrive the final disposal site from households. By the time the wastes arrive at the final dump, the putriscible fraction would have undergone a reasonable degree of decomposition. The final disposal site is dominated by diapers, water proof, food waste and paper. Food waste is a good raw material for compost. However, farmers in Nsukka prefer to use animal dung and waste stabilization pond effluent to enhance the growth of crops, instead of going through the rigours of composting. This practice represents a major health concern as the crops can get contaminated with disease-causing vectors. Table 1 is a summary of the pattern of material flow from households to curbside dumps and then to final disposal site. The second column was obtained by multiplying each waste component proportion (Figure 1) with the per capita waste generation rate. The third and fourth columns represent the percentage change in component relative proportion as waste moves from households to curbsides and finally to disposal site. Negative value implies a reduction in the relative proportion of a component, usually as a result of 
scavenging. The proportions of plastics, metals and households to final disposal site. The reduction in glass/bottles were found to decrease from the proportion of paper and water proof between household and curbsides can be attributed to the occasional burning of open dumps. It was observed that as waste flows from homes to final disposal site, there was a general increase of the relative proportions of non-recycled materials, while there was a general decrease of the relative proportions of recycled materials. Figure 6 shows piles of recyclable materials manually sorted by scavengers for marketing. Figure 7 shows that about $79 \%$ of waste generated can be either recycled or composted. However, only $12 \%$ is actually recovered for recycling while the remaining is sent to the final disposal site. This situation makes waste handling unwieldy and also results in rapid filling up of dumpsites. The process of material recovery can be initiated at the point of waste generation, especially in low income countries where waste management is still at a rudimentary level.

Table 1: Material flow from homes to final disposal sites

\begin{tabular}{|c|c|c|c|c|}
\hline $\begin{array}{c}\text { Solid Waste } \\
\text { Fraction }\end{array}$ & $\begin{array}{c}\text { Quantity Generated } \\
\text { by Households } \\
\text { (Kg/per Capita/day) }\end{array}$ & $\begin{array}{c}\text { \%Change in component } \\
\text { proportion (Household } \\
\text { to Curbside Dump) }\end{array}$ & $\begin{array}{c}\text { \%Change in component } \\
\text { proportion (Curbside to } \\
\text { Final Disposal Site) }\end{array}$ & $\begin{array}{c}\text { Recycling } \\
\text { Status }\end{array}$ \\
\hline Plastic & 0.0156 & -47.78 & -34.56 & Recycled \\
\hline Glass/bottles & 0.0156 & -82.46 & -1.34 & Recycled \\
\hline Metals & 0.0156 & -29.83 & -51.32 & Recycled \\
\hline Water Proof & 0.0429 & -3.94 & 79.03 & Not recycled \\
\hline Clothes/Textile & 0.0117 & 0.38 & 7.55 & Not recycled \\
\hline Paper & 0.0234 & -30.07 & 8.69 & Not recycled \\
\hline Food Waste & 0.1833 & 2.82 & -56.76 & Not recycled \\
\hline Diapers & 0.0078 & 906.31 & 1600.22 & Not recycled \\
\hline Others & 0.0741 & - & - & - \\
\hline
\end{tabular}
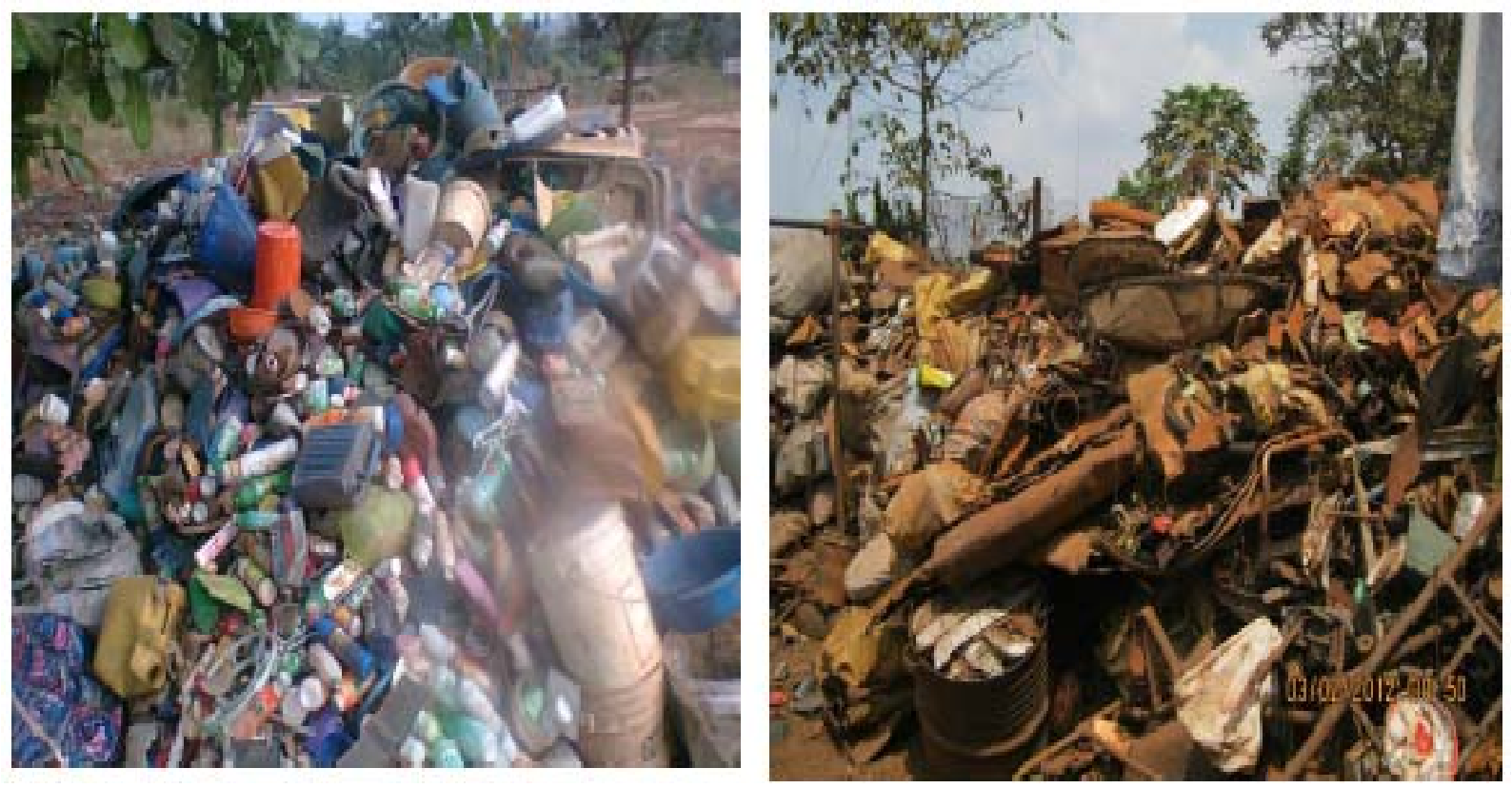

Figure 6: Recyclable materials recovered and sorted by scavengers

\section{8}

Environment Conservation Journal 
Nnaji and Utsev (2011) recommended that material recovery can be enhanced by the use of different waste bins for different categories of waste viz: (i) recyclable and non-recyclable (ii) biodegradable and non-biodegradable (iii) compostable and noncompostable, (iv) combustible and non-combustible etc. This process will simplify waste handling and maximize resource and energy recovery. This study also sought to ascertain the composition of solid waste from other sources apart from households. Figure 8 shows that more food wastes are generated by households, followed by restaurants and then

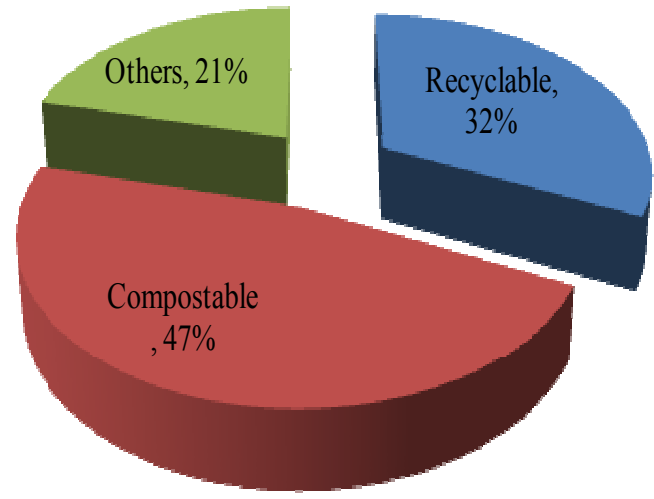
educational institutions.
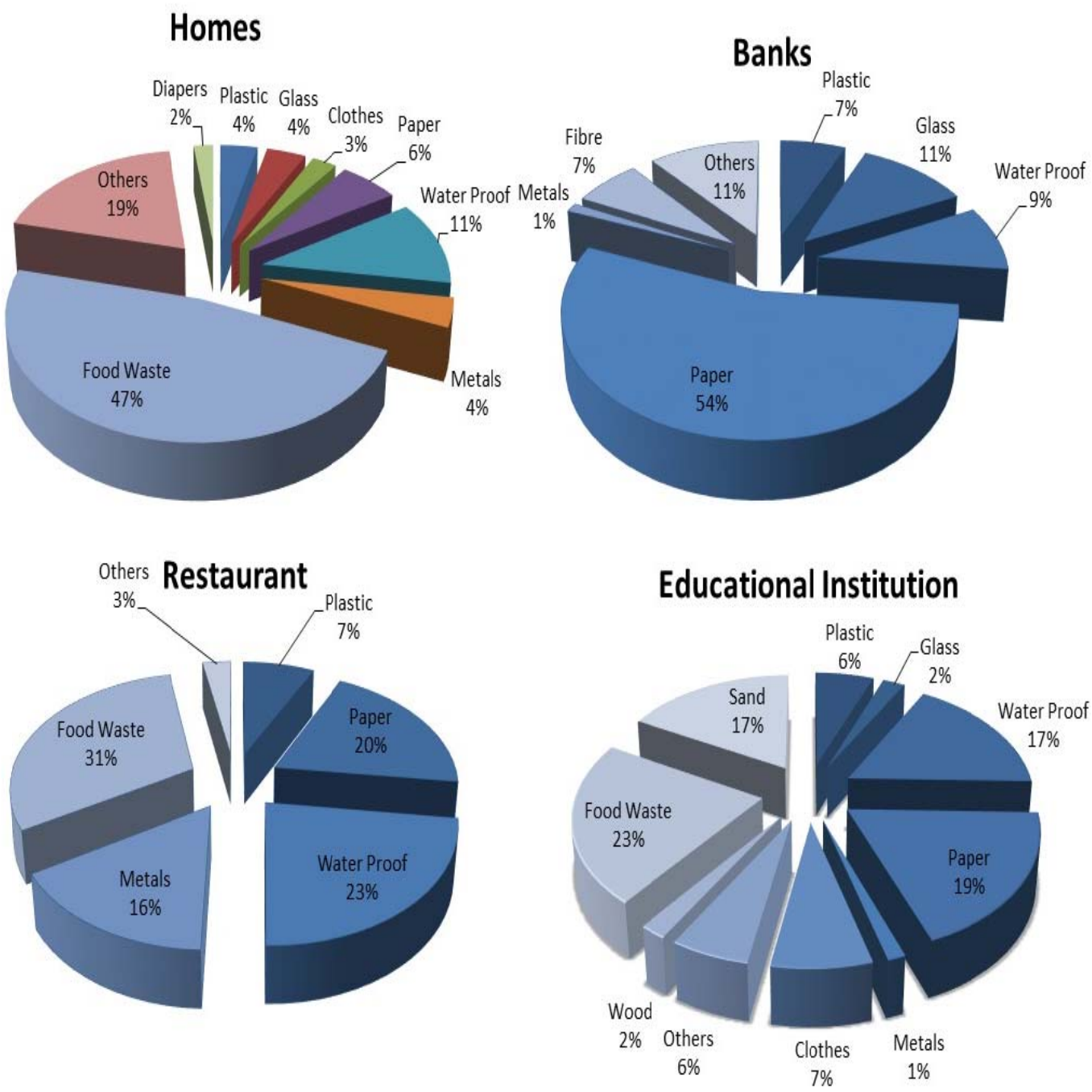

Figure 8: Composition of solid waste from different sources 
Paper constitutes more than half of solid wastes generated by banks. These papers are mostly currency wrappers, tellers and receipts from automated teller machines. About $70 \%$ of wastes from banks are combustible and about $90 \%$ consisting of paper $(54 \%)$, glass $(11 \%)$, water proof $(9 \%)$, plastic $(7 \%)$ and synthetic fibre $(7 \%)$ are recyclable. This indicates that bank wastes should be collected separately for easy handling. There is a resemblance between the composition of household wastes and those of restaurants and higher institutions. The order of composition of restaurant waste is as follows: food waste $>$ water proof $>$ paper $>$ metals $>$ plastic. The metals found in domestic solid waste consist mostly of disposable aluminium containers of beverages. Due to their ultra light weight, disposable aluminium and plastic cans are gradually replacing bottles in beverage packaging. Rapid rate of urbanization and population explosion have placed an enormous stress on waste management. This is further complicated by the introduction of disposable packaging technology; hence it is becoming increasingly difficult for municipal waste management authorities in developing countries to cope with the amount of waste they have to handle. Gidarakos et al (2006) observed a $40 \%$ decrease in putriscibles and a corresponding increase in plastics and paper over two decades. This can also be attributed to the use of disposable packaging and consumption of packaged food.

\section{Characterization of Compostable Waste}

Composting of biodegradable fraction of municipal solid waste is a means of material recovery. Unlike biogas production from solid waste, composting is a very simple process that requires no advanced technology and is therefore within the reach of anyone. In order to ascertain the compost potential of municipal solid waste in Nsukka, putriscible waste obtained from the three different sources outlined in the methodology were analyzed. The purpose of analyzing putrescible waste from these sources is to determine the most suitable source for compost materials. The results of the analyses performed on these materials have been presented in Table 2. The moisture contents were $62.47 \%$ and $53.97 \%$ for compostable waste obtained from households and final disposal site, respectively. These values fall well within the range of moisture content required for composting. However, it should be noted that the moisture content of compostable waste obtained from the final dumpsite can be subject to wide fluctuations as a result of extreme weather conditions.

Table 2: Chemical composition of compostable fraction of solid waste

\begin{tabular}{|l|l|l|l|l|l|l|}
\hline Properties & Unit & Household & Curbside & $\begin{array}{l}\text { Final } \\
\text { Dumpsite }\end{array}$ & $\begin{array}{l}\text { Average } \\
\text { Value }\end{array}$ & $\begin{array}{l}\text { Clean } \\
\text { Compost }\end{array}$ \\
\hline Moisture Content & $\%$ & 62.47 & - & 53.97 & 58.22 & - \\
\hline $\mathrm{pH}$ & - & 9.86 & 9.37 & 6.27 & 8.5 & - \\
\hline Oxidizable Carbon & $\%$ & 31.3 & 35.41 & 25.58 & 30.76 & - \\
\hline Total Organic Carbon & $\%$ & 41.76 & 47.27 & 34.13 & 41.05 & - \\
\hline Organic Matter & $\%$ & 71.99 & 81.44 & 58.83 & 70.75 & $>20$ \\
\hline Nitrogen & $\%$ & 4.49 & 2.48 & 3.92 & 582.04 & - \\
\hline C/N & & 9.3 & 19.06 & 8.7 & 12.36 & - \\
\hline Copper & $\mathrm{mg} / \mathrm{Kg}$ & 67.01 & 243.89 & 49.87 & 120.26 & $<25$ \\
\hline Zinc & $\mathrm{mg} / \mathrm{Kg}$ & 16.77 & 31.39 & 7.39 & 18.52 & $<75$ \\
\hline Nickel & $\mathrm{mg} / \mathrm{Kg}$ & 29.89 & 43.2 & 21.7 & 31.6 & $<0.2$ \\
\hline Chromium & $\mathrm{mg} / \mathrm{Kg}$ & 12.69 & 23.28 & 10.18 & 15.36 & $<50$ \\
\hline Lead & $\mathrm{mg} / \mathrm{Kg}$ & 74.00 & 148.23 & 32.54 & 84.92 & $<65$ \\
\hline Cadmium & $\mathrm{mg} / \mathrm{Kg}$ & 54.65 & 109.07 & 44.19 & 69.30 & $<0.7$ \\
\hline Clean Index $(\mathbf{0}<\mathbf{C I}<\mathbf{5})$ & & 1.5 & 1.0 & 2.4 & & \\
\hline
\end{tabular}

At the peak of the rainy season, the moisture aerobic composting; while during the dry season a content increases beyond recommended values for drastic reduction can lead to drying. Table 2 shows 130

Environment Conservation Journal 
that the $\mathrm{pH}$ of freshly generated household waste is in the alkaline range of 9.86 . However by the time the waste reaches the final dumpsite, the $\mathrm{pH}$ would have reduced to 6.27. Two factors are responsible for this drastic decline in $\mathrm{pH}$ viz: putrefaction and leaching. The mode of bacterial degradation in the core of a waste dump is a combination aerobic and mostly anaerobic decomposition. The breakdown of large organic molecules results in the formation of volatile fatty acids, which subsequently results in a $\mathrm{pH}$ decline. The effect of biodegradation is also manifested in the decline of organic matter content of compostable waste obtained from the final dumpsite. The percentage organic matter contents of the wastes from three sources are as follows: $71.99 \%$ (household), 81.44\% (curbside) and 58.83 (final dump site). The second reason for $\mathrm{pH}$ decline is that most soluble salts at the final dumpsite are removed by the combined processes of leaching and runoff.
The heavy metal contents were found to be in this order: $\mathrm{Cu}(\bar{X}=120.26 \mathrm{mg} / \mathrm{Kg})>\operatorname{Pb}(\bar{X}=84.92$ $\mathrm{mg} / \mathrm{Kg})>\operatorname{Cd}(\bar{X}=69.3 \mathrm{mg} / \mathrm{Kg})>\operatorname{Ni}(\bar{X}=31.6$ $\mathrm{mg} / \mathrm{Kg})>\operatorname{Zn}(\bar{X}=18.52 \mathrm{mg} / \mathrm{Kg})>\operatorname{Cr}(\bar{X}=15.36$ $\mathrm{mg} / \mathrm{Kg}$ ). The heavy metal contents were generally lower than those obtained by Nas and Bayram (2008) for Gümüşhane Province of Turkey but within the range of those obtained by Castaldi et al (2006) for Modena, Italy, Saha et al (2010) for different cities of India and Flyhammar (1997). The high concentrations of heavy metals in the compostable fraction of solid waste may have resulted from the bioaccumulation and biomagnifications of heavy metals in vegetables and other crops irrigated with effluent from the University of Nigeria waste stabilization pond. Masona et al (2011) observed that the use of

Table 3: Criteria for assigning weighting factors to heavy metals and score values to analytical data (Saha et al, 2010)

\begin{tabular}{|l|l|l|l|l|l|l|l|}
\hline $\begin{array}{l}\text { Heavy Metal } \\
(\mathbf{m g} / \mathbf{K g ~ d m})\end{array}$ & $\begin{array}{l}\text { Score } \\
\text { Value }\left(\boldsymbol{S}_{\boldsymbol{i}}\right)\end{array}$ & & & & & & $\begin{array}{l}\text { Weighting } \\
\text { Factor } \\
\left(\boldsymbol{W}_{\boldsymbol{i}}\right)\end{array}$ \\
\hline & 5 & 4 & 3 & 2 & 1 & 0 & \\
\hline $\mathrm{Zn}$ & $<151$ & $151-300$ & $301-500$ & $501-700$ & $701-900$ & $>900$ & 1 \\
\hline $\mathrm{Cu}$ & $<51$ & $51-100$ & $101-200$ & $201-400$ & $401-600$ & $>600$ & 2 \\
\hline $\mathrm{Cd}$ & $<0.3$ & $0.3-0.6$ & $0.7-1.0$ & $1.1-2.0$ & $2.0-4.0$ & $>4.0$ & 5 \\
\hline $\mathrm{Pb}$ & $<51$ & $51-100$ & $101-150$ & $151-250$ & $251-400$ & $>400$ & 3 \\
\hline $\mathrm{Ni}$ & $<21$ & $21-40$ & $41-80$ & $81-120$ & $121-160$ & $>160$ & 1 \\
\hline $\mathrm{Cr}$ & $<51$ & $51-100$ & $101-150$ & $151-250$ & $251-350$ & $>350$ & 3 \\
\hline
\end{tabular}

wastewater for irrigation can lead to the accumulation of heavy metals in soils and plants, beyond maximum permissible limits. Heavy metals that pose serious threats to health were assigned higher weighting factors, while those that pose minimal threats were assigned lower values. The score values were assigned based on some specified ranges of heavy metal concentration as presented in the Table 3 below. Based on Table 3 and the clean index formula introduced under materials and methods, the clean index $(C I)$ for compostable fraction of solid waste from different sources was found in this order: final dumpsite $(C I=3.3)>$ household waste $(C I=2.9)>$ curbside waste $(C I=$ 2.4). However, in order to ascertain the validity of these results, the clean indices of these compostable fractions were determined based on the criteria (range of values) specified in the Dutch composting quality otained from Veeken and Hamelers (2002). A modified clean formula has been given as follows:

$$
C I=\frac{\sum_{n}^{i=1} S_{i} X_{i}}{\sum_{n}^{i=1} X_{i}}, 0<S_{i}<1
$$

Where $S_{i}$ is a rating score assigned each analytical value based on its conformity with the standard. A value of 1 is assigned if the heavy metal concenration complies with the standard for clean compost, while a value of 0 is assigned if the clean compost standard is violated. $X_{i}$ is the concentration 
of each heavy metal in the compostable fraction from each of the sources under investigation. The above modification is necessary because it imposes stricter measures and also provides a basis for comparison of compostable fraction based on the absolute values of heavy metal concentrations, rather than a range of values. The relative phytotoxicity and ecotoxicity potentials have been accounted for by the clean compost standard given in Table 2. In order to make the clean indices obtained by this approach comparable to the previous approach, the values have been multiplied by a factor of 5. The clean index values for the different sources are given in Table 2 and rank as follows: final dumpsite $(C I=2.4)>$ household waste $(C I=1.5)>$ curbside waste $(C I=1.0)$. The order remains the same, showing that the final dump is the best source of compost material, followed by household waste and finally, curbside waste. Generally the compostable wastes obtained from the curbside contained the highest concentrations of heavy metals, followed by those obtained from households and then those obtained from the final disposal site. The reason for the lower concentration of heavy metals in wastes obtained from the final dumpsite could be as a result of leaching. Since the final disposal site is not a sanitary landfill and the bottom is not lined with suitable materials, contaminants carried by rainwater quickly migrate through the soil pores. This leaching effect is very pronounced at the final disposal site because the residence time of waste is very long compared to that at the curbside.

\section{Conclusion}

Municipal solid waste composition and generation rates are heavily influenced by solid waste sample source and family size respectively. The use of disposable items and disposable packaging has given rise to a drastic reduction in the useful life cycle of many domestic items. The result is an increased rate of waste generation and a subsequent stressing of waste management facilities. A freshly generated batch of solid waste from homes is usually laden with recyclable and reusable materials in addition to a high proportion of organic matter. However, as the waste leaves the home for the final disposal site via open dumps, its composition is usually grossly distorted due to the combined effects of scavengers, biodegradation, runoff and leaching. There is remarkable similarity among solid wastes generated by households, restaurants and higher institutions, while that generated by banks stands out, consisting mostly of paper. Moreover, the heavy metal content of municipal solid waste is on the rise because of anthropogenic activities. Based on the clean index criteria, compostable fraction obtained from final dumpsite is more suitable for composting than the fractions from the other sources.

\section{References}

Adewole, A. T. 2009. Waste management towards sustainable development in Nigeria: A case study of Lagos state. International NGO Journal 4 (4): 173 - 179.

Asase, M., Yanful, E. K., Mensah, M. Stanford, J. and Amponsah, S. 2009. Comparison of municipal solid waste management systems in Canada and Ghana: A case study of the cities of London, Ontario, and Kumasi, Ghana. Waste Management. 29: 2779 - 2786.

Castaldi, P., Santona, L. and Melis, P. 2006. Evolution of heavy metals mobility during municipal solid waste composting. Fresenius Environmental Bulletin. 15 (9): $1133-1140$.

Firdaus, G. and Ahmad, A. 2010. Management of urban solid waste pollution in developing countries. International Journal of Environmental Research. 4 (4):795 - 806.

Flyhammar, P. 1997. Estimation of heavy metal transformation in municipal solid waste. Science of the Total Environment. 198: 123 - 133.

Gidarakos, E. Havas, G. and Ntzamilis, P. 2006. Municipal solid waste composition determination supporting the integrated solid waste management system in the island of Crete. Waste Management. 26: 668 - 679.

Henry, R., Yongsheng, Z. and Jun, D. 2006. Municipal solid waste management challenges in developing countries Kenyan case study. Waste Management. 26: $92-100$.

Lebersorger, S. and Schneider, F. 2011. Discussion on the methodology for determining food waste in household waste composition studies. Waste Management. 31: 1924 -1933 .

Lisa, D. and Anders, L. 2008. Methods for household waste composition studies. Waste Management. 28: 1100 1112.

Masona, C., Mapfaire, L., Mapurazi, S. and Makanda, R. 2011. Assessment of heavy metal accumulation in waste water irrigated soil and uptake by maize plants (Zea Mays 
L) at Firle Farm in Harare. Journal of Sustainable Development. 4 (6): 132 - 137.

Nas, S. and Bayram, A. 2008. Municipal solid waste characteristics and management in Gümüşhane, Turkey. Waste Management. 28: 2435 - 2442.

Nnaji, C. C. and Utsev, T. T. 2011. Climate change and solid waste management: A balanced assessment. Journal of Sustainable Development in Africa. 13: (7): 17 - 34.

Nwachukwu, M. U. 2009. Solid waste generation and disposal in a Nigerian City: An empirical analysis in Onitsha Metropolis. Journal of Environmental Management and Safety 1 (1): $\quad 180-191$.

Ogwueleka, T. Ch. 2009. Municipal solid waste characteristics and management in Nigeria. Iranian Journal of Environmental Health, Science and Engineering 6 (3): $173-180$.
Momodu, N. S., Dimuna, K. O. and Dimuna, J. E. 2011 Mitigating the impact of solid wastes in urban centres in Nigeria. Journal of Human Ecology 34 (2): 125 - 133.

Qu, X., Li, Z., Xie, X., Sui, A, Yang, L., and Chen, Y. 2009. Survey of composition and generation rate of household wastes in Beijing, China. Waste Management 29: 2618 2624.

Saha, J. K. Panwar, N. and Singh, M. V. 2010. An assessment of municipal solid waste compost quality produced in different cities of India in the perspective of developing quality control indices. Waste Management 30: 192 201.

Sha'Ato, R., Aboho, S. Y., Oketunde, F. O., Eneji, I. S., Unazi, G. and Agwa, S. 2007. Survey of solid waste generation and composition in a rapidly growing urban area in Central Nigeria. Waste Management 27: 352 - 358.

Veeken, A and Hamelers, B. 2002 Sources of $\mathrm{Cd}, \mathrm{Cu}, \mathrm{Pb}$ and $\mathrm{Zn}$ in biowaste. The Science of the Total Environment 300: $87-98$. 